\title{
Altered Adhesion Molecule Expression of Leukocytes of SCD Patients in Crisis and Steady State
}

Nagina Parmar ${ }^{1}$, Jamie Hutchison ${ }^{2}$, Gemma Vomiero ${ }^{3}$, Ashok Kumar ${ }^{6}$, Mohamed Abdelhaleem ${ }^{4}$, Isabelle Gaboury ${ }^{5}$, Melanie Kirby-Allen ${ }^{7}$ and Robert J. Klaassen $^{5^{*}}$

${ }^{1}$ Department of Blood Transfusion Medicine, Toronto General Hospital, Toronto, ON, Canada

${ }^{2}$ Department of Critical Care, Hospital for Sick Children, Toronto, ON, Canada

${ }^{3}$ University of Calgary, Alberta, AB, Canada

${ }^{4}$ Division of Haematopathology, Department of Pathology, Hospital for Sick Children, Toronto, ON, Canada

${ }^{5}$ Division of Haematology, Department of Paediatrics, Children's Hospital for Eastern Ontario, Ottawa, ON, Canada

${ }^{6}$ Department of Pathology, CHEO Research Institute, Ottawa, ON, Canada

${ }^{7}$ Division of Haematology, Department of Pediatrics, Hospital for Sick Children, Toronto, ON, Canada

*Corresponding author: Robert Klaassen, Department of Pediatrics, Division of Hematology/Oncology, Children's Hospital for Eastern Ontario (CHEO), Rm 5109, 401 Smyth Rd, Ottawa, ON. K1H 8L, Canada, Tel: (613)737-7600 Extn. 2210; Fax: (613)738-4828; E-mail: rklaassen@cheo.on.ca

Received date: Feb 17, 2015, Accepted date: Mar 26, 2015, Publication date: Mar 30, 2015

Copyright: ( 2015 Parmar N, et al. This is an open-access article distributed under the terms of the Creative Commons Attribution License, which permits unrestricted use, distribution, and reproduction in any medium, provided the original author and source are credited.

\begin{abstract}
Background: Sickle cell disease (SCD) patients experience ischemic events resulting from vaso-occlusion of both macro-and microcirculation. A risk factor associated with increased morbidity and mortality is leukocytosis in the absence of infection. This study investigated the role of leukocytes in the pathogenesis of acute sickle cell crisis.

Procedure: Children were enrolled at two tertiary care centers in three groups: hemoglobin SS (Hb SS) patients admitted to hospital with an acute crisis, non-crisis or steady state SS patients, and sickle cell screen negative, racematched controls. Flow cytometry measured cell surface expression of adhesion molecules.

Results: $28 \mathrm{Hb}$ SS and 10 control patients were enrolled. Elevated white blood and platelet counts were observed for the crisis children $(P<0.01)$ compared to healthy control children. There was a significant increase in the expression of adhesion molecules on neutrophils and monocytes (CD11, CD 18 and CD-62L) in children in steady state $(P<0.05)$ compared to crisis, and healthy children. $71 \%$ of crisis children were receiving non-steroidal anti-inflammatory drugs (NSAIDs) or hydroxycarbamide, whereas none of the patients in steady state were receiving these drugs.
\end{abstract}

Conclusion: Further investigation is needed to explain these findings, but is likely due to the use of NSAIDs and hydroxycarbamide in our crisis patients.

Keywords: Leucocytes; Sickle cell disease; Selectin; Integrin

\section{Introduction}

Sickle Cell Disease (SCD) is characterized by the sickling of red blood cells and hemolysis; however inflammatory mechanisms and other types of cells such as leukocytes appear to participate in the vasoocclusive process. Chronically, patients can develop dysfunction because of recurrent episodes of ischemia, as well as cardiomegaly and hepatic dysfunction secondary to ongoing hemolytic anemia. One of the more frequently observed manifestations of SCD is a repeated episode of pain crisis, which remains one of the most common reasons for hospital admission.

Endothelial cell in comparison to many other cell types, were thought to be less active, less complex, and less interesting. Research in this area has expanded dramatically since then, revealing the endothelial lining as an active participant in a wide variety of pathophysiological processes, including inflammation and immunity [1]. Much of this research has been directed towards molecular mechanisms of leukocyte adhesion to the endothelium, and has resulted in the identification, characterization, and cloning of multiple endothelial-surface glycoprotein that support adhesion through an interaction with specific ligands on leukocytes. There are three main molecule-types that play a role in this interaction, namely, (i) the selectins, (ii) the immunoglobulin superfamily molecules, and (iii) the integrins. The expression of these various molecules may be modulated and unregulated by the vascular environment, primarily by toxins and cytokines $[2,3]$.

Recently, investigators have observed interactions between sickle reticulocytes, leucocytes, and endothelial cells via these adhesion molecules in patients with SCD, and hypothesized that these mechanisms may contribute to the pathophysiology of the disease [4-6] Monocytes from patients with SCD have increased expression of IL-1 $\beta$, and TNF- $\alpha$ two cytokines that are known to increase the expression of endothelial cell surface receptors [7]. In vivo data has also been generated in sickle cell mice models indicating that leukocytes that are adherent to the vessel wall can directly contribute to vascular occlusion by means of their interactions with sickle 
erythrocytes, and that inhibition of leukocyte adhesion in sickle cell mice deficient in P- and E-selectin can prevent lethal vaso-occlusion [8-10].

Current therapy for SCD is limited to chronic transfusions (associated with high morbidity and early mortality), bone marrow transplant, or hydroxycarbamide (a chemotherapy agent also known as hydroxyurea). Short courses of methylprednisolone had been suggested to clinically reduce the duration of severe pain in children and adolescents with SCD [11], and the regular use of ibuprofen has been shown to inhibit IL-1 $\alpha$ and TNF- $\alpha$ induced expression of VCAM-1, ICAM-1 and E-selectin [12]. Interestingly, it is becoming more evident that the modifying effect of hydroxycarbamide on leukocyte adhesion molecules in SCD may be as important as its effects on $\mathrm{Hb} \mathrm{F}[13,14]$.

The purpose of this study was to better understand the role of leukocyte expression in the pathogenesis of acute sickle cell crisis. Patients with sickle cell disease have a wide variation in their clinical course and there is evidence that an elevated baseline leukocyte count is associated with a poor overall prognosis [15]. We hypothesized that neutrophils and monocytes would be activated with increased expression of adhesion receptors in patients in crisis. We measured surface expression of adhesion molecules on peripheral blood neutrophils and monocytes using flow cytometry. We also examined the association between use of anti-inflammatory drugs and leukocyte adhesion receptor expression.

\section{Methods}

\section{Patients}

The patients were enrolled in three groups: 1) SCD patient in crisis with SS genotype confirmed by $\mathrm{Hb}$ electrophoresis and high performance liquid chromatography (SS in crisis), 2) SCD patients in the non-crisis, steady state returning to the Sickle clinic for routine follow up with a SS genotype confirmed by $\mathrm{Hb}$ electrophoresis (SS in steady state), and 3) healthy race-matched controls ( $\mathrm{Hb} \mathrm{AA}$, confirmed by electrophoresis). The age range for all the three groups was from 6 months to 18 years. The local Research Ethics Boards at the Children's Hospital of Eastern Ontario and the Hospital Sick Children approved the study prior to starting patient screening and enrolment. The clinic/ward staff identified eligible patients. At each study center, a research assistant prior to enrolment obtained an informed written consent from the patient/and parents.

\section{SS crisis patients selection criteria}

Patients in SS crisis group were included if they came to emergency department for pain, stroke, acute chest syndrome, and/or priapism significant enough to require admission to hospital. The patients were excluded if there was physician documented rheumatologic diagnosis, or if fever was present without evidence of crisis, or the patients require exchange transfusion prior to taking the first blood specimen.

\section{SS steady state patient selection criteria}

SS patients in steady state were included in the study if they didn't have any of the following: admission to the hospital for sickle cell crisis for the last 12 months, hydroxycarbamide therapy for the past 12 months, temperature $>38.0^{\circ} \mathrm{C}$, significant bony pain, anti- inflammatory medication within the last 7 days (including ibuprofen), or red blood cell transfusion within the last 12 months.

\section{Healthy controls patient selection criteria}

Healthy controls were enrolled if they were from African descent, between the ages of 6 months to 18 years, undergoing routine blood work, with a negative sickle screen test. Healthy controls were excluded from the study if they had any of the following: hemoglobinopathy, anemia, physician documented rheumatologic disease, fever, did not require blood work or if they were on any antiinflammatory medication (including ibuprofen) within the last 7 days. The majority of the patients came from routine assessments to the general surgery clinic.

\section{Clinical data}

The patient demographics, the results of blood tests and clinical information were collected prospectively from the health records for three groups of the patients.

\section{Blood samples}

Blood specimens were collected by following the standard policies and procedures at The Hospital for Sick Children, Toronto, Canada. Blood was taken from healthy control and SCD patients in steady state at the time of routine blood work. SCD patients presenting in crisis had their blood drawn the morning of admission, and a second blood sample was taken between day 3 and 5 of admission to determine any changes in adhesion molecule expression over time. Specimens were taken prior to any transfusions done for the patients who were admitted.

\section{Adhesion molecule expression}

Neutrophil and monocyte adhesion molecule expression were determined by flow cytometry as described by Lard et al. [16]. Erythrocytes were lysed by diluting $1 \mathrm{ml}$ of heparinized blood sample with $2.5 \mathrm{ml}$ of ice-cold isotonic $\mathrm{NH}_{4} \mathrm{Cl}$ solution (9 parts of $0.16 \mathrm{M}$ $\mathrm{NH}_{4} \mathrm{Cl}$ : 1 part $0.17 \mathrm{M}$ Tris, $\mathrm{pH}$ 7.4) for 10 minutes at room temperature. The remaining heparinized blood sample in the vacutainer was centrifuged at $400 \mathrm{~g}$ for $10 \mathrm{~min}$. The plasma was transferred in $100 \mu$ laliquots into $1.5 \mathrm{ml}$ eppendorf tubes. The tubes were labelled with the patient name, date, and study number and stored at $-80^{\circ} \mathrm{C}$. The remaining leukocytes were washed twice in icecold phosphate-buffered saline (PBS) and bovine serum albumin (BSA).

\section{Cell surface expression analysis}

Cells were resuspended in ice-cold PBS supplemented with BSA, $0.2 \% \mathrm{w} / \mathrm{v}$ to a concentration of $15 \times 10^{6}$ cells $/ \mathrm{ml}$. After isolation, the leukocytes were kept on ice for $5 \mathrm{~min}$ followed by preincubation with human $\operatorname{IgG}(1 \mathrm{mg} / \mathrm{ml})$ for $10 \mathrm{~min}$ at $4^{\circ} \mathrm{C}$. Subsequently, the leukocytes were incubated for 30 minutes at $4^{\circ} \mathrm{C}$ with the FITC or PE conjugated monoclonal antibodies specific for various adhesion molecules including CD11b, CD18, CD 49d, CD62L, CD64 and CD66b, then washed with $3 \mathrm{~mL}$ ice-cold PBS/BSA. After the staining procedure was completed, cells were fixed with $1 \% \mathrm{w} / \mathrm{v}$ paraformaldehyde (PFA) for 5 min on ice. Cell surface expression of the adhesion molecules were analyzed by flow cytometry performed with a FACScan (BecktonDickinson). The mean channel fluorescence (MCF) was determined. 
Page 3 of 6

Data was acquired on a BD FACScan Flow Cytometer and analyzed using the WinMDI version 2.8 software package (J.Trotter, Scripps Institute, San Diego, CA). Neutrophils and monocytes were discriminated from lymphocytes by their characteristic forward/ sideward scatter pattern and specific antibody expression. The antibodies were purchased from BD Pharmingen. The flow cytometry of the leukocytes analysis was done locally by each center.

\section{Statistical analysis}

White blood cell count, platelet count and hemoglobin were compared between the three groups using a one-way analysis of variance and post-hoc Tukey tests. Mean fluorescent intensity of each adhesion molecule, for both neutrophils and monocytes, were also compared between the three groups using a one-way analysis of variance and post-hoc Tukey tests and for the crisis group between day 1 and day 3-5 using a Student's t-test.

\section{Results}

\section{Patients age and drugs profile}

Thirty-eight patients were enrolled in the study including 14 SS patients in crisis, 14 SS patients in steady state and 10 healthy controls.
All of the sickle cell patients were of the genotype $\mathrm{Hb}$ SS and the healthy control patients were $\mathrm{Hb}$ AA. Out of 14 patients admitted for a crisis, eight were receiving non-steroidal anti-inflammatory drugs and two were on hydroxycarbamide at the time of the initial blood draw. None of the well SS patients were receiving NSAIDs or hydroxycarbamide. Overall median age was $8.4 \pm 5.6$ yrs. The mean age was 10.5 (1.7 to 17.4 years) for SS patients in crisis, 11.5 (3.1 to 17.9) for well SS patients and 4.2 (1.6 to 14.5 years) for healthy controls.

\section{Laboratory evaluations}

The results of the clinical hematology laboratory tests are presented in Table 1. Significant increase $(\mathrm{P}<0.001)$ in white blood cell count was observed for the SS children in crisis as compared to those in steady state and healthy control children. Platelet counts were significantly higher $(\mathrm{P}<0.001)$ in both the SS patients in crisis and in steady state as compared to healthy controls. Healthy control children had significantly higher hemoglobin concentration as compared to SS in crisis and SS patients in steady state. The percent of $\mathrm{Hb} \mathrm{S}$ and $\mathrm{Hb} \mathrm{F}$ in the steady state sickle cell patients and crisis patients was also determined (Table 1). As outlined earlier all healthy control patients were negative for sickle hemoglobin, which was confirmed by sickle screen (or HPLC).

\begin{tabular}{|l|l|l|l|}
\hline Patients Characteristics & Crisis SS & Well SS & Healthy \\
\hline WBC $\left(\times 10^{*} / \mathrm{L}\right)$ & $16.28 \pm 6.35^{* *}$ & $11.21 \pm 2.0$ & $7.52 \pm 2.0$ \\
\hline Hemoglobin $(\mathrm{g} / \mathrm{L})$ & $84.5 \pm 13.7^{* *}$ & $84.8 \pm 10.7^{* *}$ & $120.2 \pm 10.4$ \\
\hline Platelets $\left(\times 10^{*} / \mathrm{L}\right)$ & $455 \pm 195.8^{* *}$ & $440.3 \pm 110.1^{* *}$ & $338 \pm 66.7$ \\
\hline Hb S $(\%)$ & $81 \pm 5.81$ & $81.9 \pm 10$ & Sickle negative \\
\hline Hb F $(\%)$ & $13.2 \pm 6.47$ & $14.8 \pm 10$ & Sickle negative \\
\hline $\begin{array}{l}\text { "Data was analyzed by using paired t-tests. All values are mean } \pm \text { SD. } \\
\text { *Values are significant at } P<0.001 \text { compared to healthy controls. }\end{array}$ & \\
\hline
\end{tabular}

Table 1: Hematologic parameters.

\section{Patient's clinical characteristics}

The SS patients in crisis were enrolled within 12 hours of presentation to the emergency department. One of the crisis patients was febrile $\left(39.1^{\circ} \mathrm{C}\right)$ during admission. A documented infection was reported in four patients (28\%). The admissions were all for vasoocclusive pain crises located in the leg, chest, abdominal and lower back. The average duration of the hospital admission of all the patients in crisis was 2 days. Red cell transfusions were given to two of the patients (14\%) during the admission to the hospital. Five patients (35\%) had a transfusion in the 3 months prior to coming to the emergency department. The crisis improved in all the patients and they were discharged within 3 days.

\section{Medication profile}

In the seven days prior to admission eight of 14 SS patients in crisis $(57 \%)$ received non-steroidal anti-inflammatory medications (NSAIDs), and two of 14 (14\%) of the patients received HU therapy, and seven of $14(50 \%)$ were receiving narcotics. The types of NSAIDS are mostly propionic acid derivatives such as Ibuprofen. During the admission, all of the patients were given narcotics and seven of 14 (43\%) received NSAIDs. Eight of 14 (57\%) of the patients received antibiotic therapy.

\section{Patient with crisis and expression of adhesion molecules}

The expression of integrin and selectin adhesion molecules of granulocytes and monocytes such as CD11, CD18, CD 49d, CD62L, and CD64 were compared between the three study groups. There was a significant increase in the expression of integrin and selectin adhesion molecules CD18 and CD62 on neutrophils and monocytes in the well SS children as compared to SS children in crisis and healthy control children $(\mathrm{P}<0.05)$ (Figure 1). The significant increase in the expression on the selectin molecules $\mathrm{CD} 62 \mathrm{~L}$ on monocytes were observed in crisis as compared to healthy control children, however increase in the expression on the granulocytes were observed in healthy control as compared to crisis group. The comparison for the other adhesion molecules such as CD 49d, CD 52L and CD 18 were also done in well and healthy control children. The expressions of these molecules on monocytes were greater in well control as compared to healthy control children (Figure 1). 


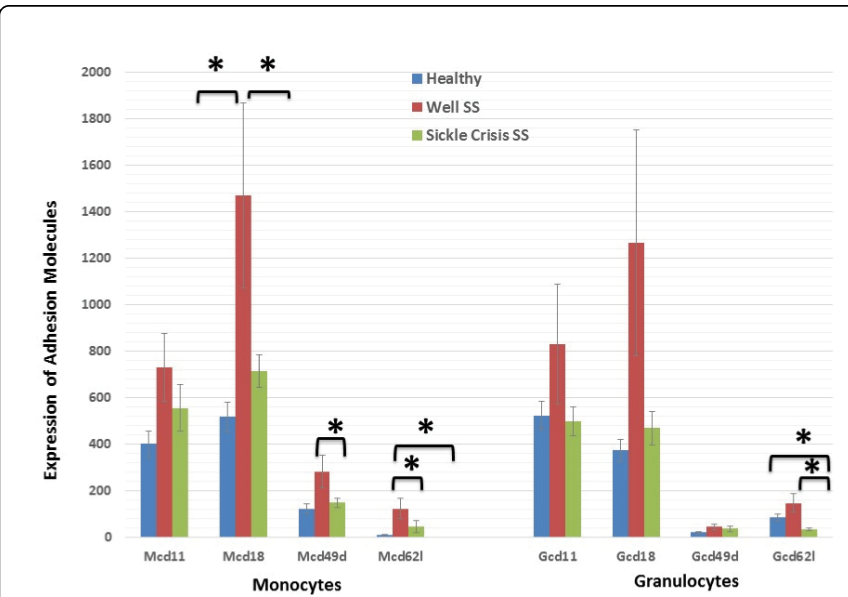

Figure 1: Comparison of the expression of adhesion molecules on granulocytes and monocytes in healthy children without sickle cell disease, patients with sickle cell disease in steady state (well SS) and sickle cell patients admitted to the hospital in crisis (crisis SS). Data are expressed as mean \pm standard deviation of the mean fluorescence intensity. ${ }^{*} \mathrm{P}<0.05$ compared to healthy and SS patients in crisis.

\section{Timing of crisis and expression of adhesion molecules}

The expression of surface adhesion molecules on monocytes and granulocytes were compared between day 1 and day 3-5 in the subset of 7 crisis patients who were still admitted to hospital. The results showed that the expression of surface adhesions molecules on monocytes MCD 621 and granulocytes GCD 18 and GCD 11 increased with time after the 3-5 days of crisis day in comparison to the first day of crisis (Figure 2). However, there was no significant difference observed in the expression of the other surface adhesion molecules on monocytes and granulocytes. All patients' data pertaining to monocytes and granulocytes expression of adhesion molecules were linked on this next figure (Figure 3). The data clearly showed that the expression for all adhesions molecules varies from patient to patient at day 1 and at the 3-5 days.

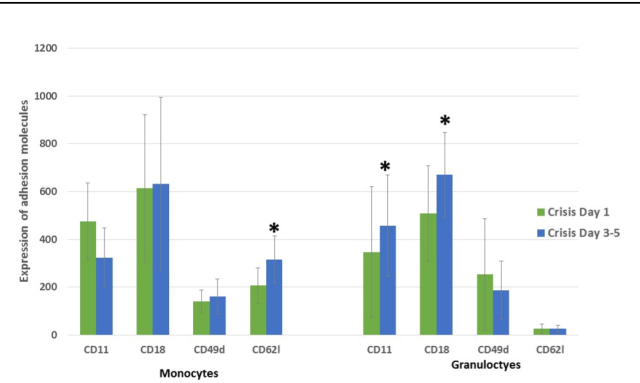

Figure 2: Comparison of the expression of adhesion molecules on granulocytes and monocytes between day 1 and day 3-5 of the admission in crisis patients. Data are expressed as mean \pm standard deviation of the mean fluorescence intensity. ${ }^{*} \mathrm{P}<0.05$ compared to day 1.

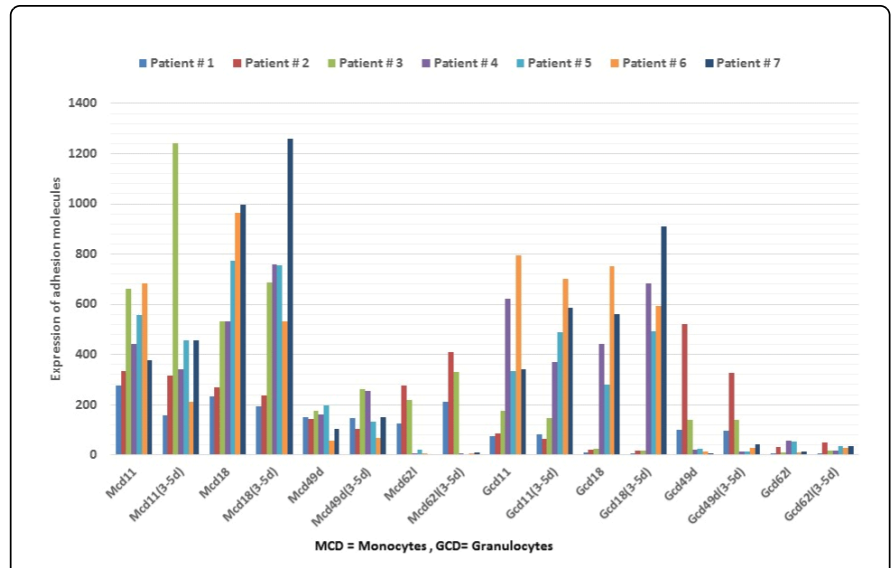

Figure 3: Comparison of the expression of adhesion molecules on on granulocytes and monocytes for all the crisis patients at day 1 and at 3-5 day of crisis. Data is expressed as an individual number from the flow cytometry data.

\section{Discussion}

Our study has shown significant differences in several adhesion molecules receptors on monocytes and neutrophils in steady state (SS), crisis (SS) and racially matched healthy control subjects. A significant increase in the expression of integrin and selectin adhesion molecules on neutrophils and monocytes (CD11b, CD18 and CD62L) in the steady state patients as compared to SS patients in crisis, and controls were observed in our study. The recurrent vaso-occlusion and tissue inflammation can cause virtually continuous inflammatory response in patients with SCD [17]. Inflammation markers that are increased during crisis and steady state SCD include leukocytes [18,19], platelets [20], C-reactive protein [21], $\propto-2$ macroglobulin, transferrin, interleukin (IL)-2, IL-4, IL-6, IL-8, fibrinogen, and activated circulating vascular endothelial cells [22]. It is also well known that anti-inflammatory agents have a role to play in inflammation in humans and animal models $[23,24]$. It has been assumed that sickle erythrocytes (RBCs) were the only factor causing the vaso-occlusive processes that account for nearly all of the clinical manifestations of SCD. However, increasing evidence suggests that leucocytes may be involved in the initiation or propagation of vaso-occlusive crisis in SCD $[16,25]$.

We found that the WBC count was elevated in SS patients in crisis as compared to well SS patients and healthy control subjects. Neutrophils of individuals with crisis are more able to adhere to recombinant intercellular adhesion molecules 1 (ICAM-1) and fibronectin and to endothelial monolayers than from healthy individuals [26,27]. According to a recently published study [28] the high degree of endothelial activation and damage seen in 5 of 28 steady state sickle cell patients demonstrates the important chronic inflammation underlying the pathophysiology of this wide spread disease. The majority of the patients $(82 \%)$ were double heterozygotes for sickle cell/beta thalassemia while only $18 \%$ were homozygotes for HbS. Our study showed that all adhesion molecules and high sensitivity C-reactive protein levels were significantly increased $(\mathrm{P}<0.001)$ in patients with sickle cell disease as compared to patients in steady state. The expression of an integrin molecules e.g. (Mac-1, $\mathrm{CD} 11 \mathrm{~b} / \mathrm{CD} 18$ ) on several extracellular matrix and endothelial proteins 
Page 5 of 6

were increased on stimulated SCD neutrophils [29,30]. The analysis of active CD18 expression on unstimulated neutrophils in SCD blood showed that the average expression of active CD18 were higher on SCD than control neutrophils, about half of the SCD population expressed active CD18 at levels equivalent to control [29]. Proinflammatory functions observed in SCD neutrophils include augmented Mac-1, L-selectin, and CD64 expression [14,16,26], and increased adhesion to fibronectin [31] and inflamed endothelium during crisis [26].

Our results contrast with earlier studies that vaso-occlusive crisis, was associated with increased expression of adhesion molecules on white blood cells [14]. The reasons for our variability in results may be that $57 \%$ of our SS patients in crisis were receiving NSAIDs and $14 \%$ of our SS patients in crisis were receiving hydroxycarbamide therapy at the time of admission. It has been described elsewhere that aspirin as well as other NSAIDs have additional important anti-inflammatory mechanisms of action [31]. These drugs are able to induce the loss of $\mathrm{L}$-selectin both in vivo and in vitro, inhibiting the adhesion of neutrophils to endothelium under experimental conditions [32,33]. Other drugs, such as Indomethacin, aceclofenac and dicofenac inhibit the activation of the VLA-4 integrin as well as the lymphocyteendothelial cell interaction mediated by this adhesion receptor [32-34]. Hydroxycarbamide is a known peptide synthesis inhibitor and reduces the expression of the reticulocyte adhesive proteins CD 36 and $\alpha 4 \beta 1$ in the early period of treatment [35].

There are other studies which shows that hydroxycarbamide can also reduce the synthesis of peptide constituents of vascular endothelial cell ligands for leucocytes adhesion molecules such as ICAM-1, -2 , and -3 and VCAM-1 and express less CD11b/CD18 on leucocytes than racially matched, $\mathrm{Hb} \mathrm{AA}$ and healthy controls [13]. Recent in-vitro studies [36] also suggested that hydroxycarbamide has an anti-adhesion effect on endothelial cells, also highlighted the heterogeneity of vascular endothelial cell responses to hydroxycarbamide and/or cytokines depending upon their origin.

Our preliminary findings suggested that children with sickle cell disease admitted with an acute crisis have a significantly higher white blood cell count than SCD and healthy controls. Sickle cell patients in steady state have significantly higher expression of neutrophils and monocytes adhesions molecules than controls, and unexpectedly crisis patients. We suggest that it is likely due to the use of NSAID and hydroxycarbamide in crisis patients. Alternatively, it is possible that, alterations in leukocyte adhesion molecules do not appear to play a role in the onset in crisis or that in crisis, the more adherent leukocytes are adhered to the vessel walls and for this reason only the leukocytes with lower adhesion molecule expression are isolated from the blood. Further investigations are required to explain the findings.

\section{Acknowledgements}

Authors would like to thank Helen Frndova for helping with data analysis, Ebrahim Sayeh and Wilfred Lim for flow cytometry analysis and Manuela for her significant help in the enrolment of subjects. Authors would also like to thank Catherine Rocchi for helping in the recruitment of healthy control patients. This study was funded by a grant from the Children's Hospital of Eastern Ontario Research Institute.

\section{References}

1. Bevilacqua MP (1993) Endothelial-leukocyte adhesion molecules. Annu Rev Immunol 11: 767-804.

2. Kaul DK, Finnegan E, Barabino GA (2009) Sickle red cell-endothelium interactions. Microcirculation 16: 97-111.

3. Kato GJ, Gladwin MT, Steinberg MH (2007) Deconstructing sickle cell disease: reappraisal of the role of hemolysis in the development of clinical subphenotypes. Blood Rev 21: 37-47.

4. Gee BE, Platt OS (1995) Sickle reticulocytes adhere to VCAM-1. Blood 85: 268-274.

5. Turhan A, Weiss LA, Mohandas N, Coller BS, Frenette PS (2002) Primary role for adherent leukocytes in sickle cell vascular occlusion: a new paradigm. Proc Natl Acad Sci U S A 99: 3047-3051.

6. Hebbel RP, Osarogiagbon R, Kaul D (2004) The endothelial biology of sickle cell disease: inflammation and a chronic vasculopathy. Microcirculation 11: 129-151.

7. Belcher JD, Marker PH, Weber JP, Hebbel RP, Vercellotti GM (2000) Activated monocytes in sickle cell disease: potential role in the activation of vascular endothelium and vaso-occlusion. Blood 96: 2451-2459.

8. Chiang EY, Frenette PS (2005) Sickle cell vaso-occlusion. Hematol Oncol Clin North Am 19: 771-78, v.

9. Brittain JE, Knoll CM, Ataga KI, Orringer EP, Parise LV (2008) Fibronectin bridges monocytes and reticulocytes via integrin alpha4beta1. Br J Haematol 141: 872-881.

10. Chaar V, Picot J, Renaud O, Bartolucci P, Nzouakou R, et al. (2010) Aggregation of mononuclear and red blood cells through an \{alpha\} 4 beta\}1-Lu/basal cell adhesion molecule interaction in sickle cell disease. Haematologica 95: 1841-1848.

11. Griffin TC, McIntire D, Buchanan GR (1994) High-dose intravenous methylprednisolone therapy for pain in children and adolescents with sickle cell disease. N Engl J Med 330: 733-737.

12. Kapiotis S, Sengoelge G, Sperr WR, Baghestanian M, Quehenberger P, et al. (1996) Ibuprofen inhibits pyrogen-dependent expression of VCAM-1 and ICAM-1 on human endothelial cells. Life Sci 58: 2167-2181.

13. Benkerrou M, Delarche C, Brahimi L, Fay M, Vilmer E, et al. (2002) Hydroxyurea corrects the dysregulated L-selectin expression and increased $\mathrm{H}(2) \mathrm{O}(2)$ production of polymorphonuclear neutrophils from patients with sickle cell anemia. Blood 99: 2297-2303.

14. Okpala I, Daniel Y, Haynes R, Odoemene D, Goldman J (2002) Relationship between the clinical manifestations of sickle cell disease and the expression of adhesion molecules on white blood cells. Eur J Haematol 69: 135-144.

15. Miller ST, Sleeper LA, Pegelow CH, Enos LE, Wang WC, et al. (2000) Prediction of adverse outcomes in children with sickle cell disease. N Engl J Med 342: 83-89.

16. Lard LR, Mul FP, de Haas M, Roos D, Duits AJ (1999) Neutrophil activation in sickle cell disease. J Leukoc Biol 66: 411-415.

17. Okpala I (2006) Leukocyte adhesion and the pathophysiology of sickle cell disease. Curr Opin Hematol 13: 40-44.

18. Anyaegbu CC, Okpala IE, Akren'Ova YA, Salimonu LS (1998) Peripheral blood neutrophil count and candidacidal activity correlate with the clinical severity of sickle cell anaemia (SCA) Eur J Haematol 60: 267-268.

19. Awogu AU (2000) Leucocyte counts in children with sickle cell anaemia usefulness of stable state values during infections. West Afr J Med 19: 55-58.

20. Okpala I (2002) Steady-state platelet count and complications of sickle cell disease. Hematol J 3: 214-215.

21. Hedo CC, Aken'ova YA, Okpala IE, Durojaiye AO, Salimonu LS (1993) Acute phase reactants and severity of homozygous sickle cell disease. J Intern Med 233: 467-470.

22. Hebbel RP, Osarogiagbon R, Kaul D (2004) The endothelial biology of sickle cell disease: inflammation and a chronic vasculopathy. Microcirculation 11: 129-151. 
Citation: Parmar N, Hutchison J, Vomiero G, Kumar A, Abdelhaleem M, et al. (2015) Altered Adhesion Molecule Expression of Leukocytes of SCD Patients in Crisis and Steady State. J Blood Disorders Transf 6: 262. doi:10.4172/2155-9864.1000262

Page 6 of 6

23. Kaul DK, Liu XD, Choong S, Belcher JD, Vercellotti GM, et al. (2004) Anti-inflammatory therapy ameliorates leukocyte adhesion and microvascular flow abnormalities in transgenic sickle mice. Am J Physiol Heart Circ Physiol 287: H293-301.

24. Griffin TC, McIntire D, Buchanan GR (1994) High-dose intravenous methylprednisolone therapy for pain in children and adolescents with sickle cell disease. N Engl J Med 330: 733-737.

25. Belcher JD, Marker PH, Weber JP, Hebbel RP, Vercellotti GM (2000) Activated monocytes in sickle cell disease: potential role in the activation of vascular endothelium and vaso-occlusion. Blood 96: 2451-2459.

26. Fadlon F, Vordermeier S, Pearson TC, Mire-Sluis R, Dumonde DC, et al. (1998) Blood polymorphonuclear leukocytes from the majority of sickle cell patients in the crisis phase of the disease show enhanced adhesion to vascular endothelium and increase expression of CD 64. Blood 91: 266-274.

27. Canalli AA, Franco-Penteado CF, Saad ST, Conran N, Costa FF (2008) Increased adhesive properties of neutrophils in sickle cell disease may be reversed by pharmacological nitric oxide donation. Haematologica 93: 605-609.

28. Kanavaki I, Makrythanasis P, Lazaropoulou C, Kattamis A, Tzanetea R, et al. (2012) Adhesion molecules and high-sensitivity C-reactive protein levels in patients with sickle cell beta-thalassaemia. Eur J Clin Invest 42: 27-33.

29. Lum AF, Wun T, Staunton D, Simon SI (2004) Inflammatory potential of neutrophils detected in sickle cell disease. Am J Hematol 76: 126-133.
30. Assis A, Conran N, Canalli AA, Lorand-Metze I, Saad ST, et al. (2005) Effect of cytokines and chemokines on sickle neutrophil adhesion to fibronectin. Acta Haematol 113: 130-136.

31. Kasschau MR, Barabino GA, Bridges KR, Golan DE (1996) Adhesion of sickle neutrophils and erythrocytes to fibronectin. Blood 87: 771-780.

32. Sánchez-Madrid F, González-Amaro R (2001) Drugs, inflammation and cell adhesion receptors. Expert Opin Pharmacother 2: 3-17.

33. Díaz-González F, González-Alvaro I, Campanero MR, Mollinedo F, del Pozo MA, et al. (1995) Prevention of in vitro neutrophil-endothelial attachment through shedding of L-selectin by nonsteroidal antiinflammatory drugs. J Clin Invest 95: 1756-1765.

34. González-Alvaro I, Carmona L, Díaz-González F, González-Amaro R, Mollinedo F, et al. (1996) Aceclofenac, a new nonsteroidal antiinflammatory drug, decreases the expression and function of some adhesion molecules on human neutrophils. J Rheumatol 23: 723-729.

35. Hillery CA, Du MC, Wang WC, Scott JP (2000) Hydroxyurea therapy decreases the in vitro adhesion of sickle erythrocytes to thrombospondin and laminin. Br J Haematol 109: 322-327.

36. Laurance S, Lansiux P, Pellay FX, Hauchecorne M, Benecke A, et al. (2011) Differential modulation of adhesion molecule expression by hydroxycarbamide in human endothelial cells From the micro- and macrocirculation: potential implications in sickle cell disease vasocclusive events. Hematologica 96: 534-542. 